\title{
HackRF + GNU Radio: \\ A software-defined \\ radio to teach \\ communication theory
}

\author{
Alberto A Del Barrio \\ José P Manzano, Víctor M Maroto , \\ Álvaro Villarín , Josué Pagán , \\ Marina Zapater', José Ayala and \\ Román Hermida
}

\begin{abstract}
In this paper, an alternative to the traditional methodology related to signal processing-like subjects is proposed. These are subjects that require a deep mathematical and theoretical basis, but the practical goal is not often emphasized, which drives students to lose interest in the subject. Thus, a software-defined radio environment is proposed to provide a more practical view of the subject. This solution consists of an open hardware-software platform able to capture and process a wide range of frequencies. HackRF is the hardware component, while GNU Radio will provide the graphical support to this device. The tests performed with a set of 36 students have revealed that they are more satisfied with this framework than just employing a traditional equation-based environment as Matlab. Furthermore, their scores in the exams also support the suitability of the proposed platform.
\end{abstract}

\section{Keywords}

Software-defined radio, HackRF, GNU radio, communication theory 


\section{Introduction}

Communication theory is a subject that belongs to the Degree in Electronic Communications Engineering of the Universidad Complutense de Madrid (UCM, Spain). This degree has been recently incorporated to the new study plans because of the European Bologna Process. ${ }^{1}$ Communication theory covers the main aspects of the Signal Processing (CE-SGP) knowledge area according to the IEEE-ACM Computer Engineering curricula. ${ }^{2}$ This subject is taught during the second semester, allocating 7.5 European Credit Transfer and Accumulation System (ECTS) credits with the following breakdown:

- Theoretical lessons: 4 ECTS credits.

- Exercise resolution sessions: 2 ECTS credits.

- Practical lab sessions: 1.5 ECTS credits.

A further description of the aforementioned subject can be found in Table 1. Being a highly theoretical subject, there is little time to perform lab sessions requiring high computational skills. During the academic year, the mathematical basis of the transformations and processes that appear during the analog and digital communications are explained. Due to the inherent abstract nature of these concepts, students are prone to lose interest and, as a consequence, the mathematical models and their possible applications in real life become harder to understand. According to the experience during the previous years, this leads to a final failure in the exams in the majority of the cases.

Table I. Communication theory contents.

\begin{tabular}{ll}
\hline Lesson & Title \\
\hline (a) Theoretical content & \\
2 & Introduction to communication systems \\
3 & Signals, noise and distortion \\
4 & The communication channel \\
5 & Analog transmission \\
6 & Introduction to digital communication \\
7 & Baseband transmission \\
(b) Lab sessions & Modulated digital transmission \\
1 & \\
2 & Introduction to Matlab \\
3 & Simulation of signals and systems \\
4 & Perturbation, noise and distortion \\
5 & Analog modulations \\
6 & Angle modulations \\
7 & Digital modulations \\
\hline
\end{tabular}


Traditional teaching methods in the wireless communications area have been focused on the theoretical/mathematical approach. ${ }^{3,4}$ Even though these subjects can be studied thanks to some simulation software such as Simulink, or an equation-based environment such as Matlab, ${ }^{5}$ students lack the practical experience to understand what a wave change means, or what is the consequence of modifying the parameters of the signals, e.g. the sampling frequency. In other words, using mathematical models or simulations there is no real perception of what is physically happening to the signals. Moreover, a practical overview of these concepts will help reinforce the students' knowledge.

Hence, a platform to help students understand the real effects of mathematical transformations and simulations is presented in this paper. This platform consists of hardware and software components, namely:

- The HackRF. ${ }^{6,7}$ This is an open source hardware project to develop a softwaredefined radio (SDR) ${ }^{8,9}$ peripheral.

- The GNU Radio. ${ }^{10}$ This software is a free and open source development toolkit that provides signal processing blocks to implement software radios.

It must be noticed that both components are open source, which according to the experience of different authors ${ }^{11}{ }^{13}$ is more beneficial from the student point of view, as the source code, documentation and datasheets are publicly available. Moreover, the framework has been developed to work under a 64-bit desktop Ubuntu distribution. In summary, the contributions of this work can be listed as:

- The development of an open source framework able to receive wireless communications in the corresponding band. For instance, those with AM or FM modulation. ${ }^{3}$

- The integration of a GNU graphical-user interface to display the captured signals, which allows the user to study their properties.

- The development of several practical lab sessions to allow students to understand the concepts related to the AM and FM modulation types. In this way, they will be able to compare real values with the simulation results.

- A pilot test with 36 students that have utilized the platform, measuring both their satisfaction as well as their marks in the exam.

The rest of the paper is organized as follows. The upcoming section covers the state of the art, how other universities deal with this type of subject, as well as similar platforms to HackRF. The subsequent section details the proposed hardware-software platform, while the section following it presents the practical sessions proposed based on this platform. The later section shows some qualitative and quantitative statistics provided by the students after performing the suggested labs and, finally, our final remarks and future lines of work are provided in the last section. 


\section{Related work}

Many educational researchers ${ }^{14,15}$ have realized that young students use to lose motivation in subjects belonging to Computer Engineering degrees. Thus, besides teaching the technical knowledge it is also critical to master psychological skills to motivate them. Moreover, theoretical subjects dealing with abstract contents are hard to comprehend, as pupils find difficulties when shifting from the mathematical to the physical meaning. ${ }^{16}$ Hence, bringing mathematics into real life by using hardware in-site is a good way to help them understand the abstract concepts. ${ }^{17,18}$

Some authors propose the use of FPGA platforms to perform Wireless Communications labs. ${ }^{19}$ Dawy et al. ${ }^{20}$ described several lab sessions utilizing proprietary tools and Excel sheets to simulate and/or compute the parameters of several networks. Other authors ${ }^{21,22}$ suggest the use of wireless motes and SDR platforms, but just demonstrating in class, i.e. without letting the students face the problems of configuring and/or programming the devices.

Subjects similar to Communications Theory, which are taught in several universities, have been examined too. This is shown in Table 2. As depicted, most labs are based on Matlab and Simulink. ${ }^{5}$ The other trend is the use of DSP processors, ${ }^{23}$ which are usually embedded in an FPGA. Nevertheless, most of them just focus on processing predefined signals, i.e. stored in a file. Another choice is LabView and USRP, as in Boise State University. ${ }^{17,18}$ USRP $^{10,24}$ is a board developed by Ettus that allows receiving and processing signals in real time. Another approach is the RTL-SDR platform, which is a TVB-T USB dongle based on the Realtek RTL2832U chip. It is being utilized at Berkeley University and it implements the SDR functionality. Thus, it can be concluded that only few universities incorporate some hardware in their signal processing subjects. In this way, the practical sessions just model the behavior of the RF systems by using equations.

Table 2. Comparative table of different universities (2016).

\begin{tabular}{|c|c|c|c|}
\hline Universities & Subject & Software & Hardware \\
\hline San Diego & DSP & Matlab/Simulink & DSP Processors \\
\hline Stanford & DSP Laboratory & Energia $(C++)$ & DSP Shield \\
\hline Berkeley & DSP & $\begin{array}{l}\text { Matlab or } \\
\text { GNU Octave }\end{array}$ & RTL-SDR \\
\hline Florida State & DSP & Matlab/Simulink & DSP Processors \\
\hline Boise State & DSP & LabView & USRP \\
\hline EPFL & SDR: a hands-on course & Matlab/Simulink & - \\
\hline Imperial College & $\begin{array}{l}\text { Advanced Communication } \\
\text { Theory }\end{array}$ & Matlab/Simulink & - \\
\hline Cornell University & $\begin{array}{l}\text { Digital Signal and } \\
\text { Image Processing }\end{array}$ & Matlab/Simulink & - \\
\hline Politecnica Madrid & Communication Theory & Matlab/Simulink & - \\
\hline
\end{tabular}


A SDR is a radiocommunication system where most components are implemented via software instead of hardware. SDRs are usually based on a configurable Zero-IF receptor. Thus, they can be utilized to design several components (filters, amplifiers, modulators/demodulators, and others) as well as whole systems (transmitters, receivers, oscilloscopes, detectors, and other modules). The parameters within the SDR can be dynamically modified, which provides a great flexibility when implementing a radiocommunication system. The SDR concept has evolved during the last decades, but in general these systems are still based on the structure depicted by Figure 1, consisting of three main blocks: the RF stage, the IF stage, and the baseband stage. The RF and IF blocks are implemented in hardware, while the baseband phase is realized in software. The baseband stage is responsible for processing the signal in baseband. For instance, modulation, demodulation, as well as spectral analysis are performed during this phase.

There is a large variety of SDR devices in the market, each one with their features and prices. Among the most popular options that support GNU Radio, ${ }^{10}$ the following ones can be encountered: AirSpy SDR Receiver, ${ }^{7}$ BladeRF, ${ }^{6}$ the aforementioned Ettus USRP, ${ }^{10,24}$ or SDR Play RSP. ${ }^{25}$ Nevertheless, the only fully open source platform is the HackRF. ${ }^{6,7}$ Some of the basic features of each board can be encountered in Table 3. It must be noted that every maker may possess different models, so only the most basic version of every device is shown. For instance, it is possible to find more complete Ettus boards with a price higher than $\$ 1000$. As can be observed in the aforementioned table, HackRF is a cheap platform, only behind AirSpy and SDR Play RSP. However, it possesses transmission capability as well as the largest radio spectrum among all the platforms. Other solutions as the dongle-based RTL-SDR utilized at Berkeley also lack the transmission capability. That is why HackRF was selected as the platform for deploying several practical sessions in the subject.

Therefore, in order to offer an easy way of studying the physical effects on signals, in this paper an open hardware-software platform is proposed, which allows going beyond the mathematical equations. Concretely, the proposed system is based on HackRF ${ }^{6,7}$ and GNU Radio, ${ }^{10}$ which allows implementing an SDR and providing graphical support. In this way, a wide range of frequencies can be easily captured, filtered, or otherwise modified and shown in real time. Unlike prior similar approaches, the proposed framework has been validated

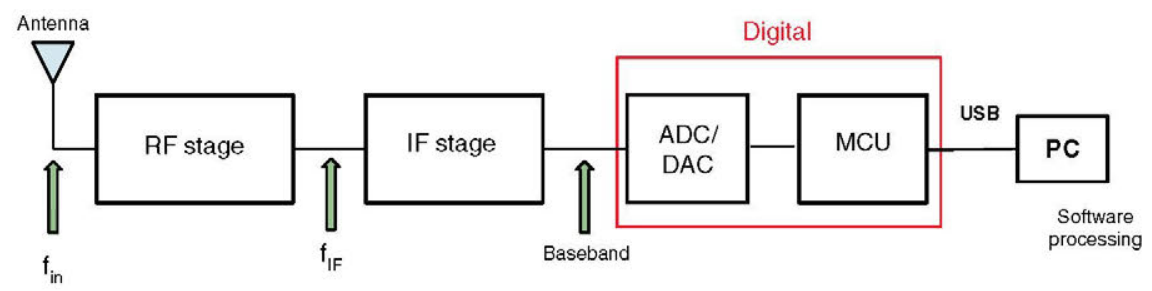

Figure I. Software-defined radio general scheme. 
Table 3. Comparative table among different SDR platforms (2016).

\begin{tabular}{|c|c|c|c|c|c|}
\hline & AirSpy & BladeRF & USRP & $\begin{array}{l}\text { SDR Play } \\
\text { RSP }\end{array}$ & HackRF \\
\hline Radio spectrum & $\begin{array}{l}24 \mathrm{MHz} \\
\quad-1.8 \mathrm{GHz}\end{array}$ & $\begin{array}{l}300 \mathrm{MHz} \\
-3.8 \mathrm{MHz}\end{array}$ & $\begin{array}{l}50 \mathrm{MHz} \\
\quad-2.2 \mathrm{GHz}\end{array}$ & $\begin{array}{l}0.1 \mathrm{MHz} \\
-2 \mathrm{GHz}\end{array}$ & $\begin{array}{l}0.1 \mathrm{MHz} \\
-6 \mathrm{GHz}\end{array}$ \\
\hline Bandwidth & $10 \mathrm{MHz}$ & $28 \mathrm{MHz}$ & $16 \mathrm{MHz}$ & $8 \mathrm{MHz}$ & $20 \mathrm{MHz}$ \\
\hline Tx & No & Full-duplex & Full-duplex & No & Half-duplex \\
\hline Open Source & Drivers & $\begin{array}{l}\text { HDL + Code } \\
+ \text { Schematics }\end{array}$ & $\begin{array}{l}\text { HDL + Code } \\
+ \text { Schematics }\end{array}$ & Drivers & Everything \\
\hline Cost & $\$ 200$ & $\$ 420$ & $\$ 675$ & $\$ 150$ & $\$ 300$ \\
\hline
\end{tabular}
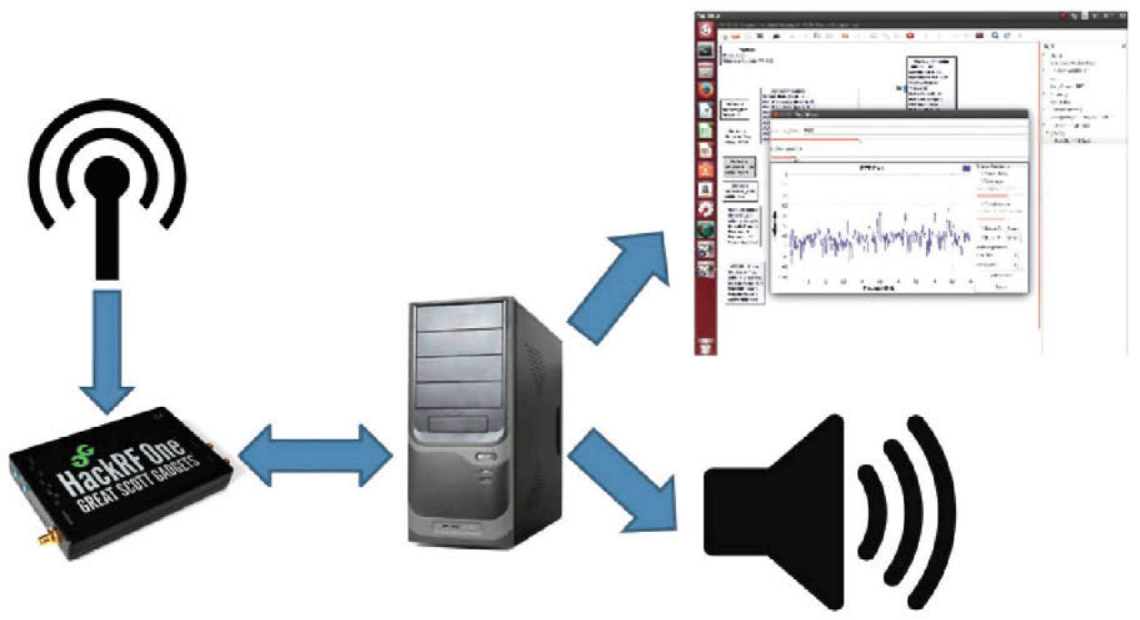

Figure 2. An overview of the system.

through a pilot test where the students have configured and programmed the devices, instead of just a demonstration performed by the teacher. ${ }^{21,22}$

\section{The HW/SW platform}

In this section, a detailed description of the proposed platform is presented. Figure 2 offers an overview of the system. It is composed of five blocks, namely:

- An antenna to capture the signals.

- The HackRF ${ }^{6,7}$ responsible for sampling and digitalizing the information.

- A computer where the GNU Radio toolkit ${ }^{10}$ is installed to display the graphical information. 
- A screen to observe the signals captured and processed by the HackRF. This is done by utilizing the plots provided by GNU Radio.

- A loudspeaker for driving the processed signals to the output.

Using the charts provided by GNU Radio, as well as the loudspeaker, the students will be able to physically perceive how the signals are changing because of different parameter configurations, noise conditions, object locations, and other issues. In the following subsections, a detailed description of HackRF and GNU Radio will be performed.

\section{The HackRF component}

As was mentioned in the introduction, HackRF ${ }^{6,7}$ is an open source hardware project that allows building a SDR peripheral. This hardware operates from 30 $\mathrm{MHz}$ to $6 \mathrm{GHz}$, a large frequency range that enables users to study signals belonging to the high frequency (HF), very high frequency (VHF), and ultra-high frequency (UHF) bands. Moreover, the use of converters such as the Ham It Up RF Upconverter ${ }^{6,7}$ permits even to study the medium frequency (MF) band. Hence, HackRF could be used to virtually implement different technologies such as: $\mathrm{AM} / \mathrm{FM}$ radio, Bluetooth, $\mathrm{ZigBee}$, or $\mathrm{WiFi}^{3,4}$ HackRF is able to transmit and receive radio signals. It operates half-duplex, or full duplex if two HackRF devices are used together. This component communicates with the host computer via USB 2.0 protocol, being USB-powered as well. Other interesting properties of this hardware are its low cost (around $\$ 300$ ) and open source nature. This means that all the hardware designs and the software source code are available under an open source license.

\section{The GNU Radio component}

GNU Radio ${ }^{10}$ is a free and open source software development toolkit that possesses several processing blocks to implement software radios. Moreover, it allows both creating new blocks and modifying the existing ones by programming them in Python. But more importantly, GNU Radio offers support to several hardware platforms, among which HackRF can be encountered. In order to utilize this device, the gr-osmosdr package needs to be installed and configured. Besides, it must be taken into account that the blocks able to deal with HackRF require a GNU Radio version equal to 3.7 or superior.

The proposed platform makes use of the GNU Radio Companion, which is a graphical tool to create signal flow graphs. In order to provide a friendly interface to the students, the WX GUI blocks will be utilized to show how the signal is behaving before and after the processing. An example of how signals are depicted using these elements can be observed in Figure 3. 


\section{Q $\Theta$ Q Top Block}

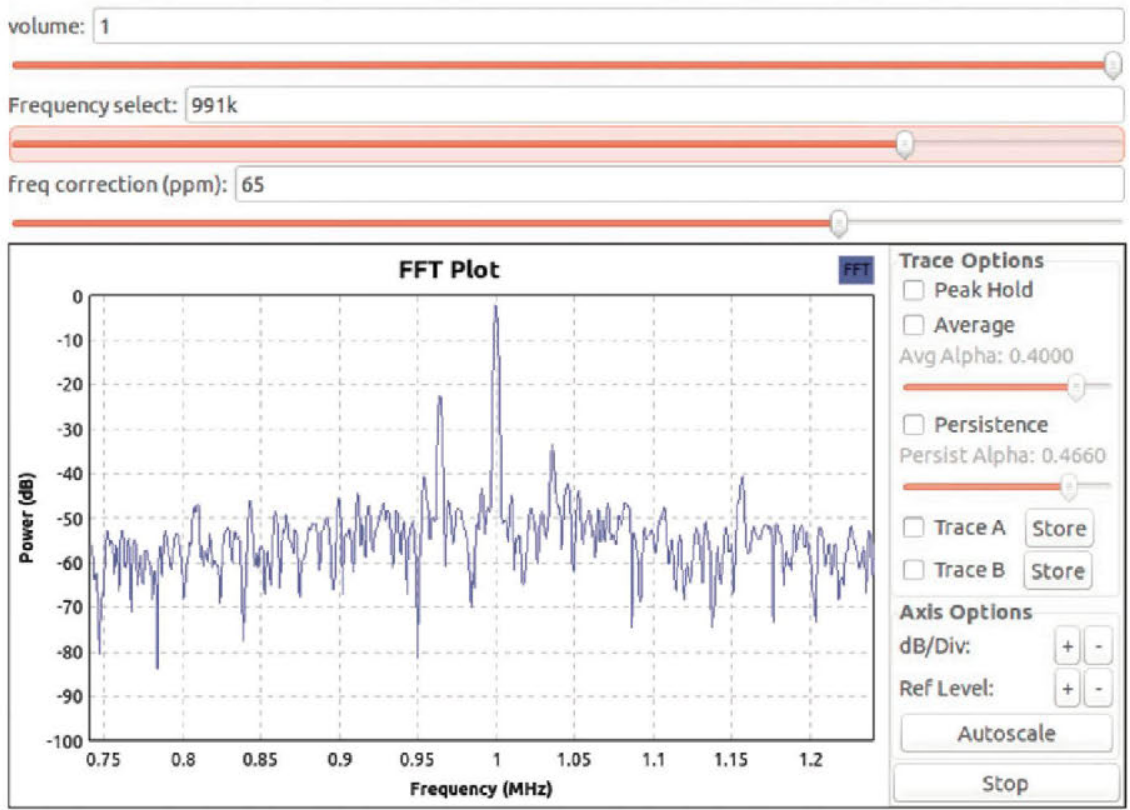

Figure 3. The WX GUI FFT Sink block capturing an AM signal after demodulation.

\section{Laboratory projects}

The description of the proposed practical sessions is addressed in this section. Despite the fact that HackRF is able to deal with a large frequency range, the lab sessions will be specially focused on the AM and FM radio signals, as it is possible to capture commercial channels. In this way, by listening to the radio broadcasting it is possible to notice the variations in the signal. This, in combination with the WX GUI blocks, provides an appealing interface to the students. Furthermore, a last lab session tackling digital modulation has been included as well.

\section{Amplitude modulation lab}

The first lab session consists of an amplitude modulation (AM)-based signal synchronous demodulation. In this type of modulation, the amplitude of the carrier wave is proportionally modified with respect to the waveform being transmitted. AM is commercially employed for radio broadcasting, ranging from 535 to $1605 \mathrm{kHz}$. This range will be utilized in the lab session, in order to listen to an AM radio channel. 


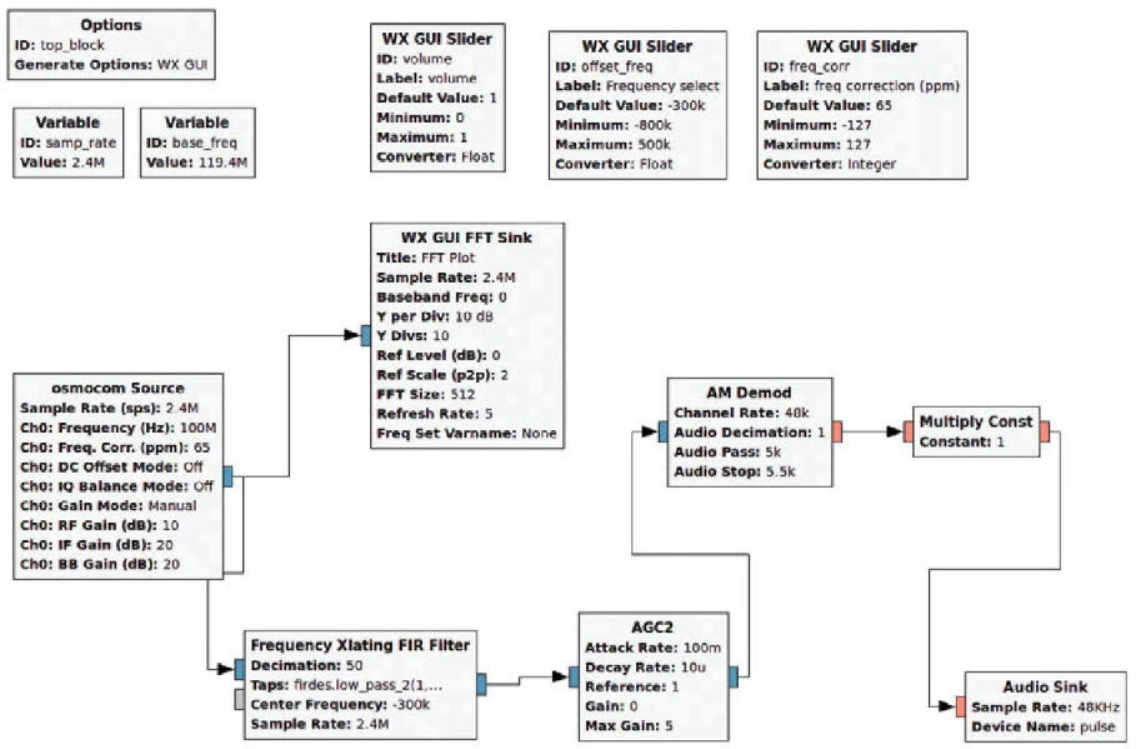

Figure 4. Blocks diagram of the AM synchronous demodulation.

The schematics corresponding to this lab are shown in Figure 4. As can be observed, a special source block named Osmocom Source block is necessary to provide the signal captured by the HackRF. This block is defined with a sample rate and correlation frequency, and may be used for both transmission and reception.

Besides the source, filter, demodulating and other blocks, it is always necessary to include a sink one, which is the ending point of the application. In this case, an Audio Sink block has been selected to allow listening to the demodulated signal just by connecting the loudspeaker or the headphones to the computer.

Moreover, several graphic blocks have been incorporated. These are the WX GUI blocks and associated sliding bar components, which are shown in Figure 3. The sliding elements are associated to parameters of the system, so it is possible to modify the reception gain (volume), frequency band, and other parameters in real time while observing the effects on the signal.

This lab session helps the students understand the main difference among carrier, modulated signal, and information signal. They also recognize in a very practical way how the morphology of the signal encodes the transmitted information, and how the channel and the receiver can affect the accuracy of the demodulation. Besides, some concepts like the modulation index and the power transmitted by the lateral bands are easily exemplified in the lab, teaching the students how to recognize those parameters in the modulated signal and calculate their values. 


\section{Q日) Top Block}

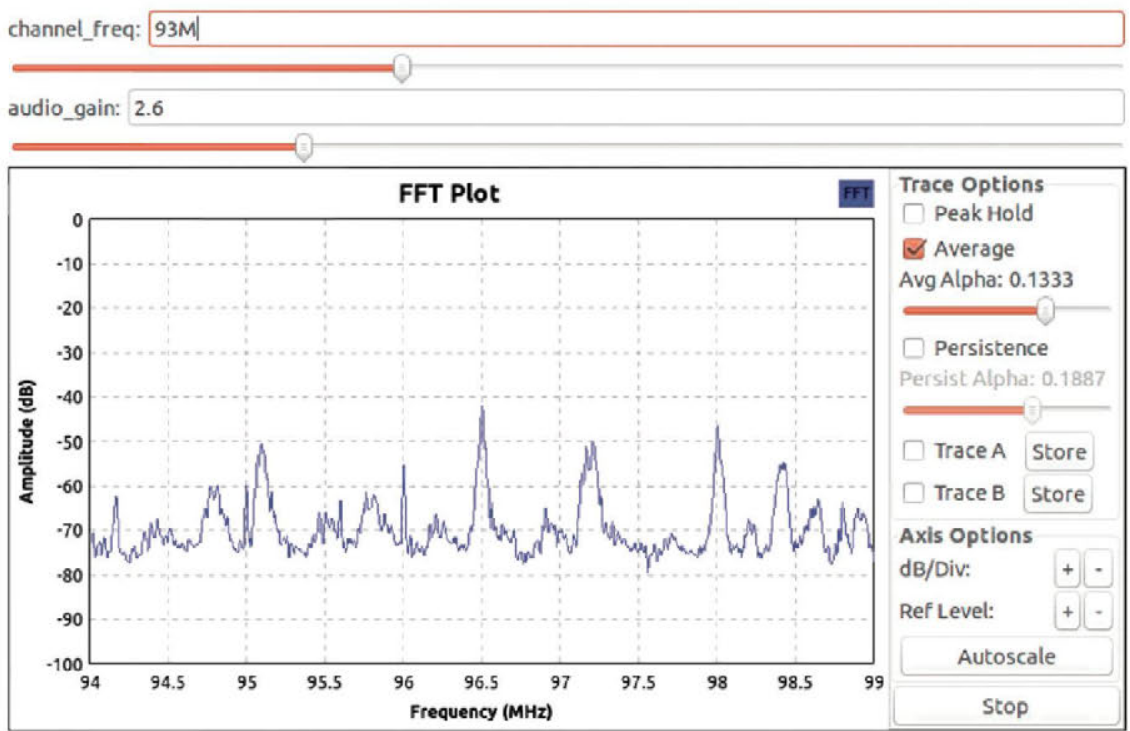

Figure 5. FM spectrum.

\section{Frequency modulation lab}

In this second lab session, a frequency modulation (FM)-based signal is received and demodulated. In this type of modulation, the modulating signal is proportional to the variation between the carrier and its center frequencies. FM possesses better fidelity and noise immunity and that is why it is heavily used in FM radio broadcasting, but also in other contexts such as telemetry or radar. FM radio broadcasting approximately ranges between 85 and $117 \mathrm{MHz}$. The target of this second practical session will be listening to some of these commercial FM channels.

As in the previous lab, source, sink as well as filters and graphical elements are required. Nevertheless, it must be noted that FM demodulation is harder to perform than AMs. Thus, other components such as a Rational Resampler, Frequency Multiplier, or a WBFM Receive block will be necessary. More details about the FM demodulation can be found in Barrio et al. ${ }^{26}$

Figure 5 depicts the outcome of this lab session. It must be observed that the WX GUI block allows showing the average values and/or the peak ones. Thus, it is possible to clearly identify where the FM channels may be located.

Some of the most complex concepts for the students are related to the FM spectrum and how the frequency deviation or the maximum frequency deviation tune this spectrum. This lab session is able to provide the students with a practical exercise on these concepts, as well as allowing them to observe the FM spectrum of 
complex modulated signals. With this practice, they are able to relate the Bessel equations provided during the theoretical lessons with the actual FM spectrum that is observed in the lab.

\section{Digital modulation lab}

This third lab session consists of studying an example of digital modulation: the Gaussian frequency shift keying (GFSK). In this type of modulation, the "1" is represented by a frequency increase in the carrier, while the " 0 " is represented by a frequency decrease.

There are many small devices on the market that use this type of modulation, like radio control cars or TV remotes. In order to emulate the behavior of these devices, two wireless motes carrying an ARM Cortex-M3 and a radio transceiver by Texas Instruments have been employed to work in the ISM band. (We thankfully acknowledge the startup M2C Solutions, S.L. for providing the wireless motes and the software radio libraries used for this project.) The motes are configured to use GFSK, while the HackRF is utilized for sniffing the connection. For this purpose, it must be configured using $868.1 \mathrm{MHz}$ as the central frequency. In GNU Radio, a GFSK demodulation block must be employed as well as a scope module for displaying the frames.

A final application of this lab is to replicate the frames. For example, in the radio control scenario, it is possible to capture the frames when applying certain commands to the car (e.g. left, right, forward, or backward movements). For this purpose, a FileSink block will need to be included. Once the frames corresponding to each action have been captured, similar frames can be transmitted from the HackRF to the car.

This lab session helps the students improve their knowledge in the digital data transmission techniques. More in detail, they are able to easily understand how the source and channel coding determine the expected bit error rate (BER), and how the approximated expressions can fail in noisy channels. Moreover, with this practice the students can observe the effects of the intersymbol interference (ISI), and how the selection of filters and bitrate can mitigate its effect.

\section{Experiments}

In order to check the suitability of the proposed framework, a pilot-test was performed within the Communication Theory lab sessions at UCM during the academic years 2015-2016 and 2017-2018. The lab sessions during the year 2015-2016 were fully based on Matlab. ${ }^{5}$ On the other hand, since the year 2016 2017 there has been a hybrid approach combining both Matlab and HackRF+GNU Radio, although Matlab has still been the dominant framework. In any case, in both years the pilot consisted of developing the $\mathrm{AM}$ lab session from scratch using the material available at Barrio et al., ${ }^{26}$ and testing the solution corresponding to the FM lab. To allow the students compare the Matlab-based 
(a)

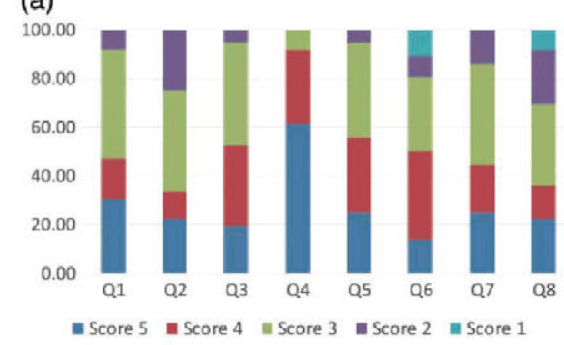

(b)

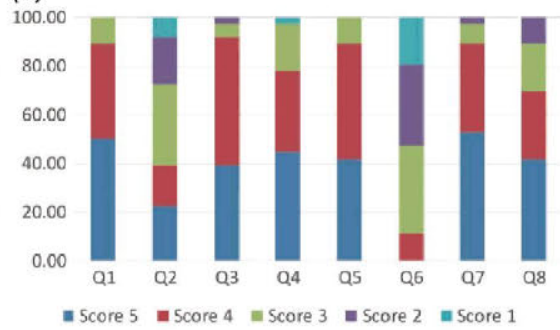

Figure 6. Survey results comparing Matlab and HackRF + GNU Radio: (a) Matlab questions; (b) HackRF + GNU Radio questions.

labs with the proposed ones during the year 2015-2016, the test just focused on pupils repeating the subject. Then, for the sake of comparability, the test during the academic year 2017-2018 also focused on the same subset of students.

\section{Comparison Matlab vs. HackRF + GNU Radio}

Figure 6 depicts the results of a survey run on a set of 36 repeating students, 21 belonging to the academic year 2015-2016 and 15 belonging to the year 2017-2018. It must be noted that the number of students in the subject is always around 40 , so the amount of students participating in the pilot is noticeable for this subject. Figure 6(a) and (b) shows the breakdown of their answers to a battery of questions labeled as $Q i, i$ being the identifier of the question. These questions are defined in Table 4. As observed, questions $Q 1$ to $Q 8$ have been posed to evaluate both Matlab as well as the proposed platform. The answers to these questions range from 1 to 5, with 1 being Poor and 5 being Excellent. The rightmost two columns of Table 4 show the average scores for Matlab and HackRF + GNU Radio, respectively.

After analyzing the aforementioned data for each question, the following conclusions can be drawn:

- Question $Q 1$. The students think that the proposed platform has been more useful to understand the abstract concepts required for the subject. On average there is a difference of 0.7 points, while in the breakdown charts shown in Figure 6 it is clear that the proposed platform gets more 5 and 4 marks.

- Question $Q 2$. Regarding the required programming and configuring skills, both approaches get similar scores and not high, which is good for a highly theoretical subject as Communication Theory. The students have pointed that HackRF is easier to program, but the configuration of the blocks requires many parameters. 
Table 4. Battery of questions answered by students and average scores.

\begin{tabular}{|c|c|c|c|}
\hline ID & Question & Matlab & $\begin{array}{l}\text { HackRF } \\
\text { + GNURadio }\end{array}$ \\
\hline Q I & $\begin{array}{l}\text { Was Matlab/HackRF a useful tool for the } \\
\text { study of the subject? }\end{array}$ & $3.69 \pm 0.99$ & $4.39 \pm 0.68$ \\
\hline Q2 & $\begin{array}{l}\text { How is the required configuring and/or } \\
\text { programming level? }\end{array}$ & $3.31 \pm 1.08$ & $3.25 \pm 1.23$ \\
\hline Q3 & $\begin{array}{l}\text { How much did Matlab/HackRF contribute } \\
\text { to your understanding of the AM/FM } \\
\text { foundations? }\end{array}$ & $3.67 \pm 0.85$ & $4.28 \pm 0.69$ \\
\hline Q4 & $\begin{array}{l}\text { Do you think that using Matlab/HackRF will } \\
\text { be beneficial for your future? }\end{array}$ & $4.53 \pm 0.64$ & $4.17 \pm 0.93$ \\
\hline Q5 & Average satisfaction with Matlab/HackRF & $3.75 \pm 0.89$ & $4.31 \pm 0.66$ \\
\hline Q6 & $\begin{array}{l}\text { Learning Matlab/HackRF took me } \\
\text { much time }\end{array}$ & $3.33 \pm 1.15$ & $2.39 \pm 0.92$ \\
\hline Q7 & $\begin{array}{l}\text { I recommend using Matlab/HackRF for } \\
\text { other subjects related to digital } \\
\text { communications }\end{array}$ & $3.56 \pm 1.01$ & $4.39 \pm 0.76$ \\
\hline Q8 & $\begin{array}{l}\text { Seeing and/or interacting with the signals } \\
\text { with Matlab/HackRF was more useful } \\
\text { than the theoretical classes }\end{array}$ & $3.19 \pm 1.24$ & $4.00 \pm 1.03$ \\
\hline
\end{tabular}

- Question Q3. When focusing on the content of the pilot test, HackRF + GNU Radio scores around 0.6 more on average, which confirms the results provided by question $Q 1$.

- Question $Q 4$. Regardless the prior results, the students believe that Matlab will be slighlty more beneficial for them when getting to the labor market. This is not surprising, as Mathworks is a well-established company. Nevertheless, the proposed platform gets almost 4.2 points on average, which is really good for a pilot platform.

- Question Q5. Overall, the proposed platform scores around 4.3 on average, more than 0.5 points more than Matlab. Hence, the students confirm that HackRF + GNU Radio is an appealing platform for them, which also facilitates their learning task. The main reasons stated by the students for this rating were both the friendly signals visualization and ease of interaction, as they can easily understand the concepts explained during the theoretical sessions of the subject.

- Question $Q 6$. This question is complementary to question $Q 2$. The average value is 0.9 lower in the case of HackRF + GNU Radio, which indicates that the proposed platform is more suitable for a highly theoretical subject as Communication Theory.

- Question $Q 7$. The average score achieved by our platform is around 0.8 points higher than Matlab. The students are indicating that HackRF + GNU Radio is 
more didactic than Matlab to learn and comprehend the fundamentals of digital communications.

- Question $Q 8$. This question complements questions $Q 1, Q 5$, and $Q 7$, pointing in the same direction. The proposed platform achieves on average 0.8 more points than Matlab. Hence, this reinforces the didactic features of HackRF + GNU Radio.

Therefore, it can be concluded that the pilot test was a positive experience, as according to the students' feedback the proposed platform is better suited than Matlab.

\section{Marks improvement}

Finally, a marks comparison has been performed between the two subsets of repeating students. In the exams, the students are expected to apply AM and FM equations as well as arguing their answers. Hereafter, there is an example of exercise related to FM modulation, which appeared in June 2016 exam (4 points out of 14,1 point per question). As can be observed, questions $a$ and $d$ are highly related to lab sessions. Both the height and the frequency multiplier are studied in the FM lab.

$F M$ exercise. Given an FM signal: $y(t)=\cos \left[2 \pi * 10^{7} t+\sin (2 \pi * 5000 t)\right]$. The load is $R=50 \Omega$. Calculate:

- The height (power) that corresponds with every spectral line belonging to the unilateral power spectral density.

- The power associated to the Carson's bandwidth $\left(B_{\text {Carson }}\right)$.

- The fraction of the total power $P_{y}$ that is contained in $B_{\text {Carson }}$.

- If the signal goes through an x20 frequency multiplier, justify the changes that are produced in the FM signal.

In order to evaluate the improvement, Figure 7 depicts the histograms related to how the repeating students performed the June exam from 2015 to 2018. The horizontal axis depicts the mark percentage that was achieved for the AM and FM questions, as well as the overall score. It must be noted that in 2015 and 2016 there were separate questions about AM and FM, while in 2017 and 2018 there was only a question about AM/FM. As displayed in these figures, the repeating students performed better during June 2016 and 2018 in comparison with June 2015 and 2017, respectively. Thus, students performed better during the two academic years in which the pilot was deployed. This fact indicates that the proposed labs were a positive experience for the repeating students, as they reinforced their knowledge in comparison with the repeating students in June 2015, which only practiced with Matlab, or in comparison with the repeating students in June 2017, which performed the AM/FM lab sessions still working with Matlab. 
(a)

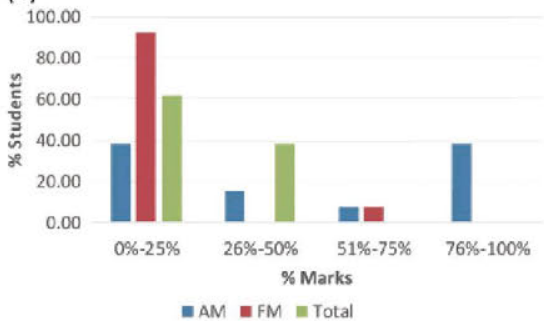

(c)

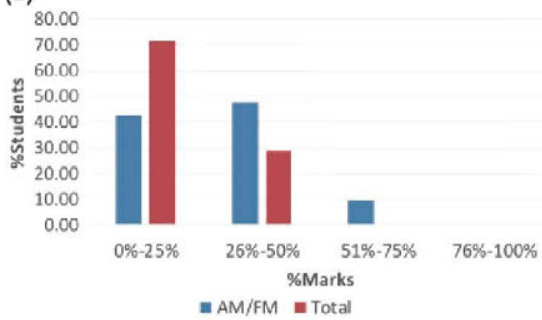

(b)

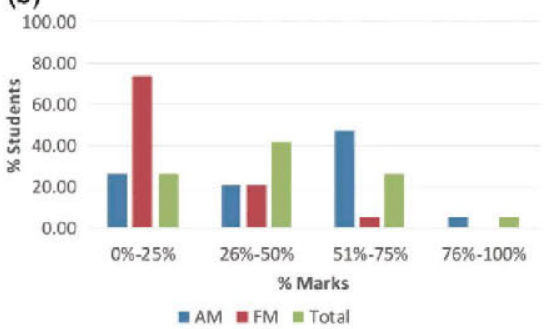

(d)

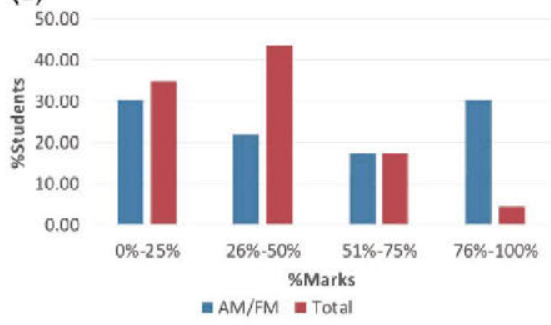

Figure 7. Repeating students histograms: (a) June 2015; (b) June 2016; (c) June 2017; (d) June 2018 .

\section{Control group}

In spite of the encouraging results the prior studies present their limitations as well. Employing several sequential exams and a group of repeating students to measure the efficiency of the pilot may present an additional problem: there might be students participating during several academic years, so their knowledge might be increased just by repetition. In order to check this, a control group ${ }^{27}$ has been defined for the pilot performed during the year 2017-2018. This control group (labeled as control) has been composed of five repeating students that did not participate in the pilot but performed the exam. On the other hand, there have been 11 students out of 15 that performed both the pilot and the exam (labeled as pilot). In this way, both subsets have experienced the hybrid labs approach during the prior academic year (2016-2017), so it can be considered that both subsets possess a similar background and they just differ in the completion of the pilot.

Figure 8(a) and (b) shows the marks breakdown for the pilot and control groups. As can be seen, the pilot group performed better than the control group. In the control group, only one student passed the exam and two falling in the $26-50 \%$ tier also succeeded in the subject. On the other hand, in the pilot group three students passed the exam and three more falling in the $26-50 \%$ tier also succeeded in the subject. Apparently the results might seem quite similar, but when looking at the average scores it is possible to confirm how the pilot group $(4.36 \pm 1.9)$ has performed better than the control group (3.2 \pm 1.83$)$. All in all, 
(a)

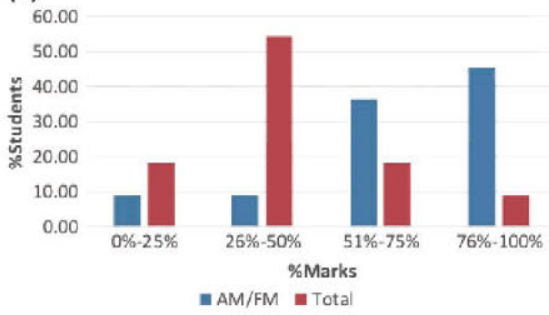

(b)

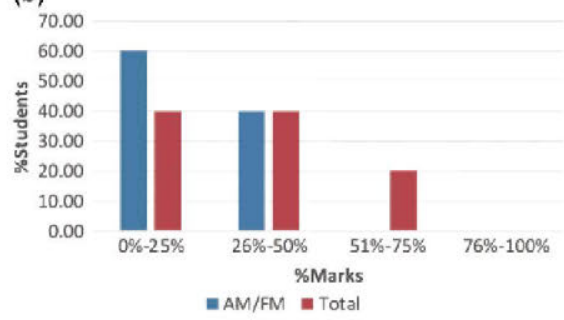

Figure 8. Group of control study: (a) June 2018 - Pilot; (b) June 2018 - Control.

although there were few students in the control group, the results are quite encouraging and point in the same positive direction as the prior surveys.

\section{Conclusion}

In this work, an alternative method for developing the practical sessions in the Communication Theory subject has been presented. Many universities implement the practical sessions by using equation-based environments such as Matlab, or just focus on the signal processing capabilities offered by DSPs. In contrast to this approach, the proposal consists of an open hardware-software platform composed of the HackRF device as well as the GNU Radio toolkit, which allows studying the physical effects in real time.

This solution is affordable from the economic point of view for a public university as UCM, and according to the students feedback it is more appealing than current labs. Moreover, the student scores also indicate that the experience with HackRF has been positive.

In addition to this, a future direction for this project is to fully deploy the environment, adapting all the lab sessions of the subject to the features of HackRF and GNU Radio. Furthermore, this platform could be utilized by other subjects as Wireless Communications, belonging to the same degree as Communication Theory.

\section{Declaration of Conflicting Interests}

The author(s) declared no potential conflicts of interest with respect to the research, authorship, and/or publication of this article.

\section{Funding}

The author(s) disclosed receipt of the following financial support for the research, authorship, and/or publication of this article: This work has been supported by the EU (FEDER) and the Spanish MINECO, under grants TIN 2015-65277-R and TEC 2012-33892, and the UCM Teaching Innovation Project PIMCD-2015-18, whose results are accessible at Barrio et al. ${ }^{26}$ 


\section{ORCID iD}

Alberto A Del Barrio (D) https://orcid.org/0000-0002-6769-1200

\section{References}

1. Reinalda B, Kulesza E and Klingemann HD. The Bologna process - harmonizing Europe's higher education. Leverkusen: Barbara Budrich Publishers, 2006.

2. Impagliazzo J, Conry S, Hughes $\mathrm{J}$, et al. Computer engineering curricula. Technical report, IEEE Computer Society and ACM, 2016.

3. Proakis J and Salehi M. Communication systems engineering. Englewood Cliffs, NJ: Prentice-Hall, 2002.

4. Ziemer RE and Tranter WH. Principles of communications. New York: John Wiley and Sons, 2002.

5. Bentounsi A, Djeghloud $\mathrm{H}$, Benalla $\mathrm{H}$, et al. Computer-aided teaching using MATLAB/ Simulink for enhancing an IM course with laboratory tests. IEEE Trans Educ 2011; 54: 479-491.

6. Mishra A and Johnson D. White space communication: advances, developments and engineering challenges. New York: Springer, 2015.

7. Wright $\mathrm{J}$ and Cache J. Hacking exposed wireless. New York: McGraw Hill Professional, 2015.

8. Bagheri R, Mirzaei A, Heidari M, et al. Software-defined radio receiver: dream to reality. IEEE Commun Mag 2006; 44: 111-118.

9. Ramacher U. Software-defined radio prospects for multistandard mobile phones. Computer 2007; 40: 62-69.

10. Wyglinski A, Nekovee $\mathrm{M}$ and Hou Y. Cognitive radio communications and networks: principles and practice. New York: Elsevier Inc., 2010.

11. Vanfretti L and Milano F. Facilitating constructive alignment in power systems engineering education using free and open-source software. IEEE Trans Educ 2012; 55: 309-318.

12. Llamas-Nistal $\mathrm{M}$ and Mikic-Fonte F. Generating OER by recording lectures: a case study. IEEE Trans Educ 2014; 57: 220-228.

13. Ackovska $\mathrm{N}$ and Ristov $\mathrm{S}$. OER approach for specific student groups in hardwarebased courses. IEEE Trans Educ 2014; 57: 242-247.

14. Atkinson S. Factors influencing successful achievement in contrasting design and technology activities in higher education. Int $J$ Technol Des Educ 2006; 16: 193-213.

15. Magdalena R, Serrano AJ, Martín-Guerrero JD, et al. A teaching laboratory in analog electronics: changes to address the bologna requirements. IEEE Trans Educ 2008; 51: $456-460$.

16. Temes JB. Teaching electromagnetic waves to electrical engineering students: an abridged approach. IEEE Trans Educ 2003; 46: 283-288.

17. Welch $\mathrm{T}$ and Shearman S. LabVIEW, the USRP, and their implications on software defined radio. In: ASEE annual conference \& exposition, Vancouver $\mathrm{BC}$, Canada, 2011.

18. Welch TB and Shearman S. Teaching software defined radio using the USRP and LabVIEW. In: 2012 IEEE international conference on acoustics, speech and signal processing (ICASSP), 2012, pp. 2789-2792. New York: IEEE. 
19. Linn Y. An ultra low cost wireless communications laboratory for education and research. IEEE Trans Educ 2012; 55: 169-179.

20. Dawy Z, Husseini A, Yaacoub E, et al. A wireless communications laboratory on cellular network planning. IEEE Trans Educ 2010; 53: 653-661.

21. Taslidere E, Cohen FS and Reisman FK. Wireless sensor networks: a hands-on modular experiments platform for enhanced pedagogical learning. IEEE Trans Educ 2011; 54: 24-33.

22. VonEhr K, Neuson W and Dunne B. Software defined radio: choosing the right system for your communications course. In: 2016 ASEE annual conference \& exposition, New Orleans, LA, USA, 2016.

23. Meyer-Base U, Vera A, Meyer-Base A, et al. An undergraduate course and laboratory in digital signal processing with field programmable gate arrays. IEEE Trans Educ 2010; 53: $638-645$.

24. Truong NB and $\mathrm{Yu} \mathrm{C}$. Investigating latency in GNU software radio with USRP embedded series SDR platform. In: 2013 eighth international conference on broadband and wireless computing, communication and applications (BWCCA), Compiegne, France, 28-30 October 2013, pp. 9-14.

25. Hamilton C. BeagleBone black cookbook. Birmingham: Packt Publishing, 2015.

26. Barrio AAD, Ayala JL and Hermida R. Low cost software receiver and computerized interface for the practical study of the radioelectric communications. Technical report, Universidad Complutense de Madrid, 2015.

27. Tafreschi D and Thiemann P. Doing it twice, getting it right? The effects of grade retention and course repetition in higher education. Econ Educ Rev 2016; 55: 198-219. 